\title{
Focal Dural Arteriovenous Fistula (DAVF) Presenting with Progressive Cognitive Impairment Including Amnesia and Alexia
}

\author{
Takashi Hasumi ${ }^{1,2}$, Takeshi Fukushima ${ }^{1}$, Toshihiko Haisa ${ }^{2}$, Tsutomu Yonemitsu ${ }^{2}$ \\ and Masaaki Waragai ${ }^{1}$
}

\begin{abstract}
A 75-year-old woman with a dural arteriovenous fistula (DAVF) presented with progressive cognitive impairment including amnesia and alexia. Neuroradiological studies showed a relatively confined DAVF lesion in the left temporal lobe. The patient did not have a history of trauma and did not complain of headache or tinnitus. Amnesia and alexia dramatically improved upon treatment of the DAVF, and this was associated with attenuation of an abnormal MRI signal in the left temporal lobe. The results suggest that gradually impaired cerebral circulation due to focal venous hypertensive encephalopathy localized to the left temporal lobe and resulting from a DAVF could be involved in slowly progressive amnesia and alexia. The case also shows that an intracranial DAVF may present as a variety of neurological symptoms, depending on its localization, size and clinical stage.
\end{abstract}

Key words: dural arteriovenous fistula (DAVF), progressive cognitive impairment, amnesia, alexia

(DOI: 10.2169/internalmedicine.46.0262)

\section{Introduction}

A dural arteriovenous fistula (DAVF) is a cerebral vasculopathy that consists of abnormal arteriovenous shunts within a leaflet of the dura mater (1-3). Common initial symptoms of a DAVF include tinnitus, headache, proptosis and neurological deficits with intracranial hemorrhage $(4,5)$. MRI is useful for diagnosis and pre-therapeutic planning for patients with a DAVF (6). Recently, DAVF cases presenting with unique neurological symptoms such as pure progressive dementia or Parkinsonism have been reported (7-13); these reports also indicate that non-invasive neuroradiological investigations may facilitate early diagnosis and treatment of a DAVF, and that a DAVF lesion may result in a variety of neurological deficits, depending on the clinical stage. Here, we present the case of a patient with a DAVF in the left temporal lobe who showed progressive amnesia and alexia, and whose symptoms improved dramatically following treatment of the DAVF.

\section{Case Report}

A 76-year-old right-handed woman consulted with her family doctor due to slowly progressive amnesia and alexia, which had persisted for more than one year and included deterioration of short-term memory, forgetfulness of peoples' names, and difficulty with reading. She had no history of head trauma, meningitis, thrombophlebitis or skull surgery. A brain CT showed mild atrophy of the brain, and the patient was suspected to have early stage Alzheimer disease and donepezil was administered. However, six months later amnesia and alexia had progressed and developed, and at this time the patient was admitted to our hospital. On neurological examination, she was alert and cooperative, and did not show the typical signs of a DAVF, which include pulsatile tinnitus, headache, papilloedema or bruit in the head and neck. She did show amnesia and alexia with agraphia, since she could not write or read kanji (Japanese morphograms) or kana (Japanese phonetic writing). Her cognitive function for recent memory and orientation to time and place were

${ }^{1}$ Division of Neurology, JR Tokyo General Hospital, Tokyo and ${ }^{2}$ Department of Neurosurgery, JR Tokyo General Hospital, Tokyo Received for publication April 24, 2007; Accepted for publication May 14, 2007 Correspondence to Dr. Masaaki Waragai, warawaram2002@aol.com 
(a) Before treatment
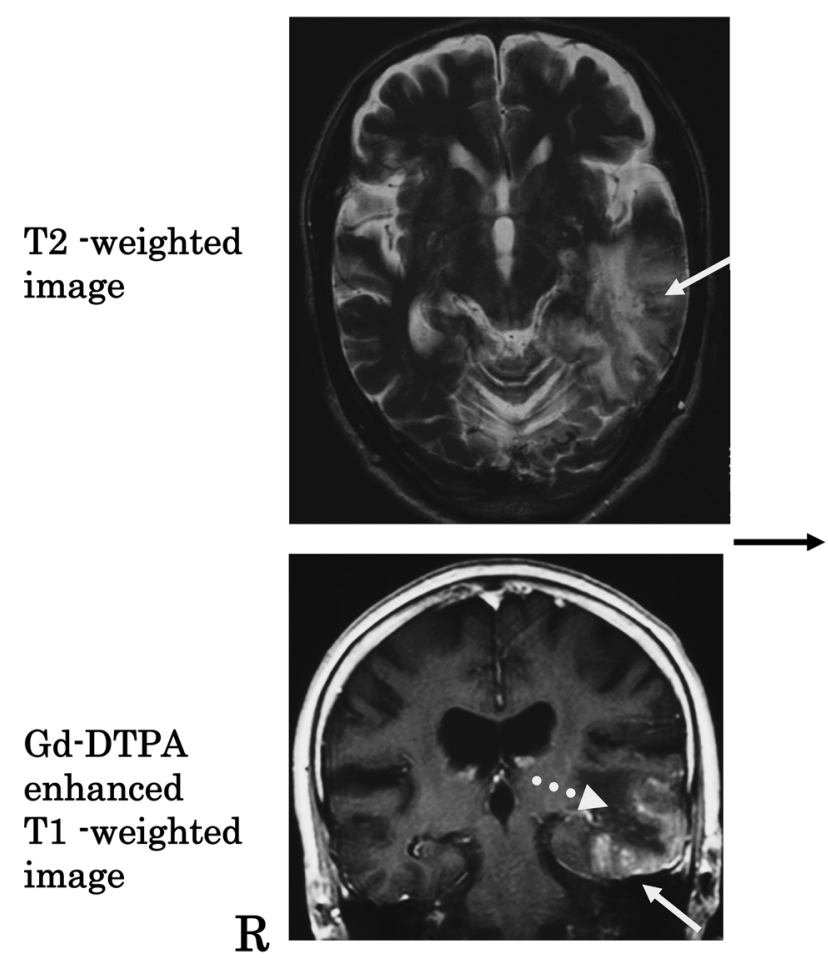

(b) After treatment (total removal of DAVF)
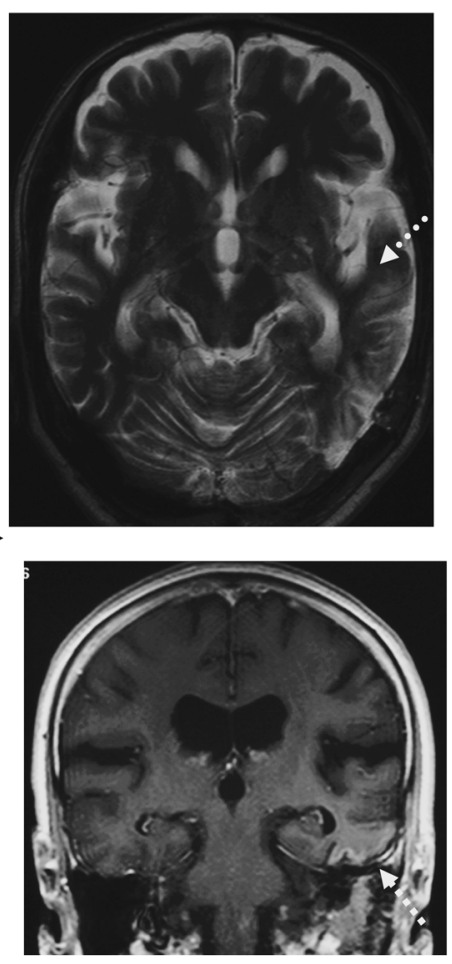

Figure 1. MRI performed on admission, showing abnormal signals in the left posterior-temporal lobe with surrounding edema (upper panel), which was enhanced by Gd-DTPA (lower panel). Left carotid angiography before and after total resection of the DAVF (a) and (b). Attenuation of most of the abnormal changes in signal intensity in the left temporal lobe after treatment of the DAVF (b). upper panel: T2-weighted image ; lower panel: Gd-DTPA-enhanced T1-weighted image.

also impaired, and her MMSE score was 21. However, she exhibited no sign of paresis, ataxia, parkinsonism and consciousness disturbance.

MRI showed a confined lesion with focal edema in the left temporal lobe, and this lesion was enhanced by GdDTPA (Fig. 1a). Cerebral angiography showed a DAVF in the left transverse-sigmoid sinus with sinus thrombosis and dilatation of the cortical veins; the DAVF was fed from the left occipital artery and the dural branch of the left vertebral artery. Retrograde filling of the left Labbé vein was also apparent (Fig. 2a). Three-dimensional ${ }^{99} \mathrm{mTc}$-ethylcysteinate dimer (ECD) SPECT imaging using eZIS analysis (14) showed extensive reduction of cerebral blood flow, predominantly from the left temporal lobe to the left parietooccipital area, and this was related to cognitive dysfunction, including amnesia and alexia in this patient (15) (Fig. 3a). Although endovascular surgery including transarterial and transvenous approach was tried, it was technically difficult in this patient, and she underwent surgical removal of the DAVF, which resulted in obliteration of the DAVF and elimination of retrograde filling of the straight sinus (Fig. 2b). ECD SPECT imaging using eZIS analysis one month after treatment demonstrated improved cerebral blood flow of the left temporal lobe and the left parieto-occipital area (Fig. 3b). Subsequently, her amnesia and alexia improved completely, with an associated attenuation of the ab- normal MRI signal in the left temporal lobe (Fig. 1b).

\section{Discussion}

DAVFs usually occur within the walls of the dural venous sinuses and account for $10-15 \%$ of all intracranial arteriovenous abnormalities (1-3). The commonly recognized initial symptoms of a DAVF are tinnitus, headache, proptosis, decreased cognitive function, and neurological deficits associated with intracranial hemorrhage $(4,16,17)$. However, recent reports suggest that it is not uncommon for elderly patients with a DAVF to present with disturbance of higher cognitive function but without other neurological deficits (713). Furthermore, we have reported DAVF cases presenting with pure progressive dementia in which symptoms were improved by treatment of the DAVF, leading to the proposal that a DAVF should be considered as a possible cause of treatable/reversible dementia in elderly patients $(10,13)$.

The present patient had unique clinical features of progressive amnesia and alexia caused by a relatively confined DAVF lesion in the left temporo-parietal lobe. The pathophysiology was essentially the same as those in previous reports of focal venous hypertensive encephalopathy resulting from a DAVF, which caused arterial hypo-perfusion of the cerebral cortex $(10,13)$. According to the location of the fistula and the venous congestion, various symptoms can be 
(a) Before treatment

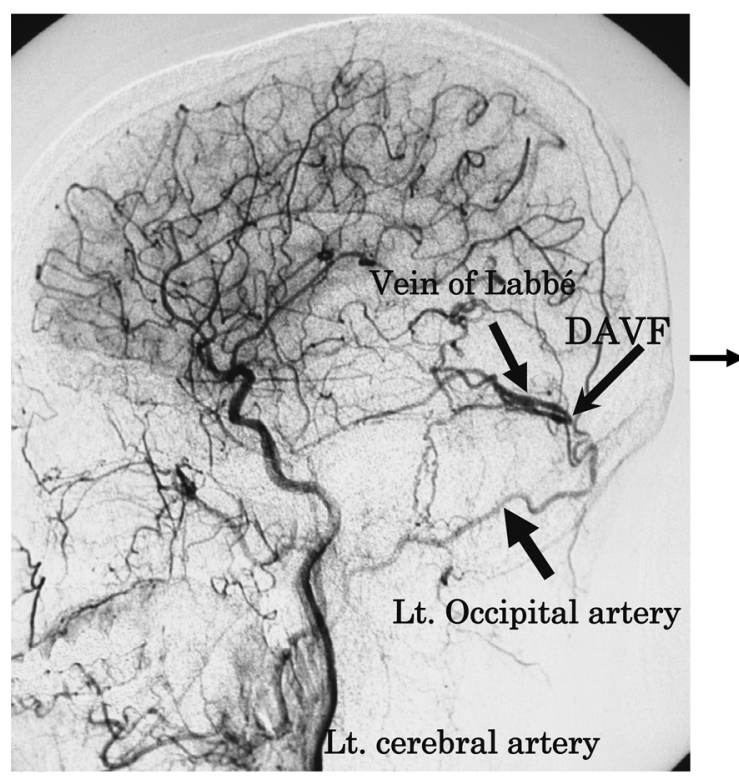

(b) After treatment (total removal of DAVF)

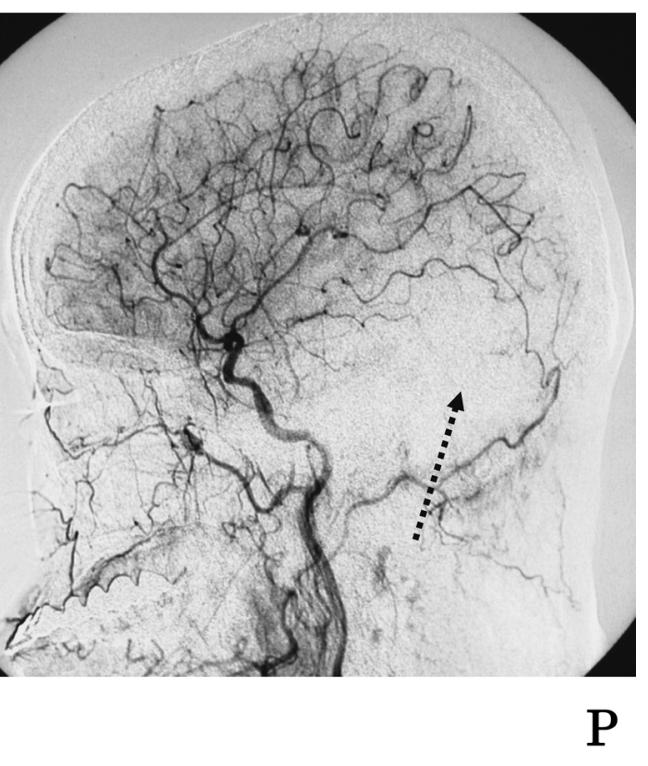

A

Lateral view (Left)

Figure 2. Left carotid angiography before treatment of the DAVF lesion, showing a DAVF in the left transverse-sigmoid sinus with sinus thrombosis (dotted arrow) and dilatation of the cortical veins (arrowhead); the DAVF was fed from the left occipital artery. Retrograde filling of the left Labbé vein was also recognized (a). The lesion and abnormal venous filling disappeared after treatment (b).

(a) Before treatment $(2005 / 8 / 8)$

Brain perfusion SPECT (eZIS image)
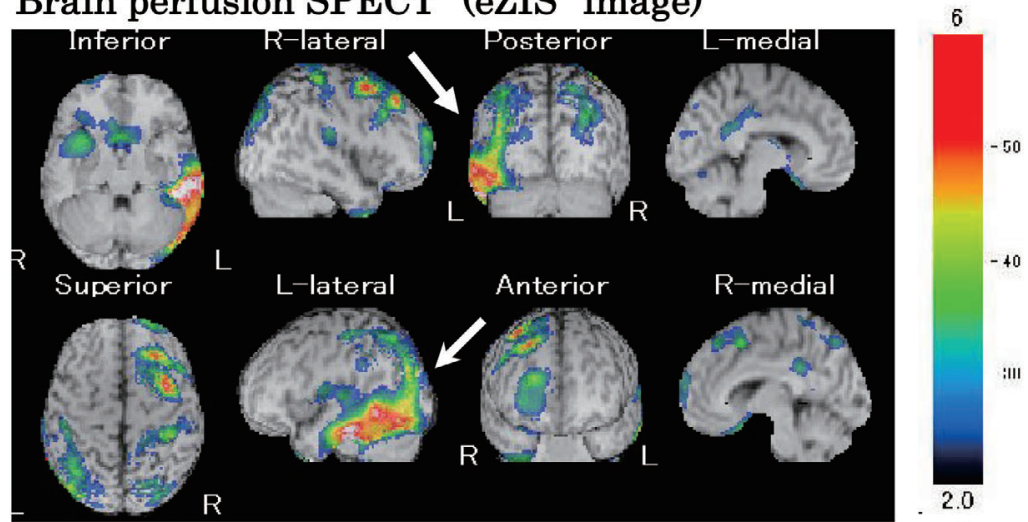

(b) One month after treatment : total removal of DAVF

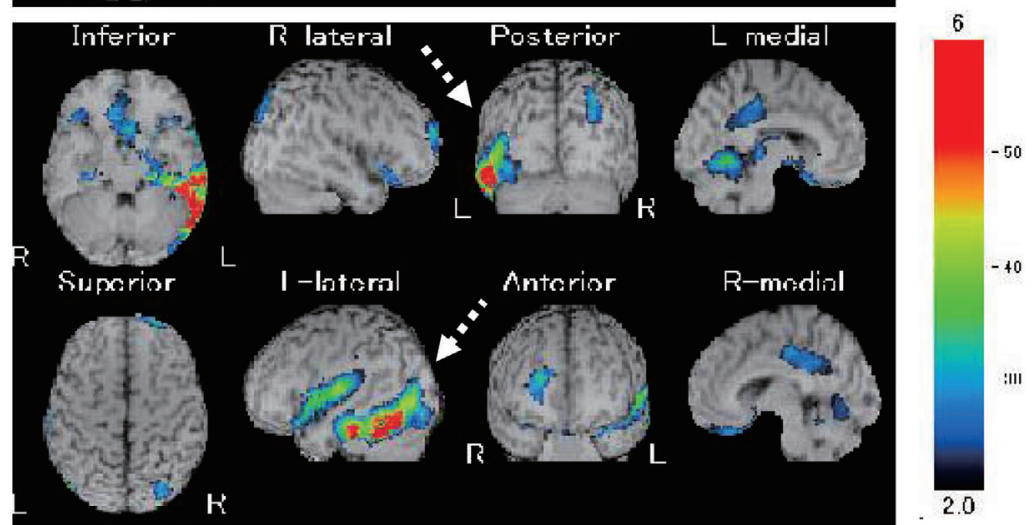

6

2.0

Figure 3. Regional cerebral blood flow studied using three-dimensional SPECT imaging with eZIS analysis demonstrated a marked area of hypoperfusion (color) in the temporo-parietal area (a). The hypoperfusion area was ameliorated after treatment (b). Color-coding represents the statistical significance (Z-score) of the decrease in regional cerebral blood flow (rCBF), red represents a more significant decrease in $\mathrm{rCBF}$ change. 
observed. The most important point is that DAVF are a possible cause of treatable dementia. Thus, the possible presence of a DAVF should be considered in elderly patients with manifestations such as those described above and early diagnosis using MRI, MR angiography and cerebral angiography is needed to facilitate early treatment of the DAVF.

\section{References}

1. Newton $\mathrm{TH}$, Cronqvist S. Involvement of dural arteries in intracranial arteriovenous malformations. Radiology 93: 1071-1078, 1969.

2. Awad IA, Little JR, Akarawi WP, Ahl J. Intracranial dural arteriovenous malformations: factors predisposing to an aggressive neurological course. J Neurosurg 72: 839-850, 1990.

3. Duffau H, Lopes M, Janosevic V, et al. Early rebleeding from intracranial dural arteriovenous fistulas: report of 20 cases and review of the literature. J Neurosurg 90: 78-84, 1999.

4. Obrador S, Soto M, Silvela J. Clinical syndromes of arteriovenous malformations of the transverse-sigmoid sinus. J Neurol Neurosurg Psychiatry 38: 436-451, 1975.

5. Lalwani AK, Dowd CF, Halbach VV. Grading venous restrictive disease in patients with dural arteriovenous fistulas of the transverse/sigmoid sinus. J Neurosurg 79: 11-15, 1993.

6. De Marco JK, Dillon WP, Halback VV, Tsuruda JS. Dural arteriovenous fistulas: evaluation with MR imaging. Radiology 175 193-199, 1990.

7. Hirono N, Yamadori A, Komiyama M. Dural arteriovenous fistula: a cause of hypoperfusion-induced intellectual impairment. Eur Neurol 33: 5-8, 1993.

8. Iwata A, Nakamura K, Nukina N, Kanazawa I, Iwata M. A case of dural arteriovenous fistula accompanied by sinus occlusion. A serial study using CT scans. Rinsho Shinkeigaku 38: 133-137, 1998.

9. Hurst RW, Bagley LJ, Galetta S, et al. Dementia resulting from dural arteriovenous fistulas: the pathologic findings of venous hypertensive encephalopathy. AJNR Am J Neuroradiol 19: 12671273, 1998.
10. Matsuda S, Waragai M, Shinotoh $H$, Takahashi N, Takagi K, Hattori T. Intracranial dural arteriovenous fistula (DAVF) presenting as progressive dementia and Parkinsonism. J Neurol Sci 165: 4347, 1999.

11. Yamakami I, Kobayashi E, Yamaura A. Diffuse white matter changes caused by dural arteriovenous fistula. J Clin Neurosci 8 : 471-475, 2001

12. Lee PH, Lee JS, Shin DH, Kim BM, Huh K. Parkinsonism as an initial manifestation of dural arteriovenous fistula. Eur J Neurol 12: 403-406, 2005.

13. Waragai $M$, Takeuchi $H$, Fukushima $T$, Haisa $T$, Yonemitsu $T$. MRI and SPECT studies of dural arteriovenous fistulas presenting as pure progressive dementia with leukoencephalopathy: a cause of treatable dementia. Eur J Neurol 13: 754-759, 2006.

14. Kanetaka $H$, Matsuda $H$, Asada $T$, et al. Effects of partial volume correction on discrimination between very early Alzheimer's dementia and controls using brain perfusion SPECT. Eur J Nucl Med Mol Imaging 31: 975-980, 2004.

15. Kawamura M, Hirayama K, Hasegawa K, Takahashi N, Yamaura A. Alexia with agraphia of kanji (Japanese morphograms). J Neurol Neurosurg Psychiatry 50: 1125-1129, 1987.

16. Houser OW, Campbell JK, Campbell RJ, Sundt TM Jr. Arteriovenous malformation affecting the transverse dural venous sinus - an acquired lesion. Mayo Clin Proc 54: 651-661, 1979.

17. Cognard C, Gobin YP, Pierot L, et al. Cerebral dural arteriovenous fistulas: clinical and angiographic correlation with a revised classification of venous drainage. Radiology 194: 671-680, 1995.

(C) 2007 The Japanese Society of Internal Medicine http://www.naika.or.jp/imindex.html 